\title{
Seasonal Variation of the Hemagglutinating Activities in the Red Alga Gracilaria verrucosa
}

\author{
Yuichi Takahashi* and Susumu Katagiri* \\ (Accepted July 1, 1987)
}

\begin{abstract}
Three different hemagglutinins, of which the molecular weight was about $300-400 \mathrm{~K}, 100 \mathrm{~K}$ and $45 \mathrm{~K}$ respectively, were found in the extract from a red alga Gracilaria verrucosa by means of molecular sieve gel chromatography.

$300-400 \mathrm{~K}$ and $100 \mathrm{~K}$ hemagglutinins showed the isoelectric point of pI 4.2 , and agglutinated horse erythrocytes but not those of goose. On the other hand, $45 \mathrm{~K}$ hemagglutinin had the isoelectric point of pI 4.7 and agglutinated both horse and goose erythrocytes.

Hemagglutinating activities in the algal extract were found during the period of November to next June, and not in July and August. Hemagglutinins with higher molecular weight (300-400 K and $100 \mathrm{~K}$ ) and lower isoelectric point (pI 4.2) were detectable in December, February and March but little or nothing in November, while $45 \mathrm{~K}$ hemagglutinin was detected in all test periods (November to next March).
\end{abstract}

In some marine algae, the physico-chemical properties of their hemagglutinins have been reported. ${ }^{1-6)}$ Some of them have unique properties differing from hemagglutinins from other sources $^{7)}$, the activity is inhibited by glycoproteins such as fetuin, but not by monosaccharides, and is not affected by addition of divalent cations. Two groups of workers found a hemagglutinating activity against various animal erythrocytes including human erythrocytes in the red alga Gracilaria verrucosa. ${ }^{8, \theta)}$ However, the detailed physicochemical properties, seasonal variation and biological functions of the hemagglutinins are still unknown. In the present study we report the occurrence of three different hemagglutinins in the red alga $G$. verrucosa and the seasonal variation in hemagglutinating activity of these components.

\section{Materials and Methods}

\section{Seaweed}

One of the red alga Gracilaria verrucosa, was collected at Nagasaki Prefecture in March, June, August and November, 1981, and at Ehime Prefecture in January, February, May, June, July, August, November, and December, 1983. After washing with distilled water, the specimens were stored at $-20^{\circ} \mathrm{C}$ until use.

\section{Extraction of hemagglutinins}

Extraction was carried out by stirring the algal bodies $(50 \mathrm{~g})$ in $500 \mathrm{~m} l$ of $0.05 \mathrm{M}$ phosphate buffered saline, pH 7.0 (PBS) for $48 \mathrm{~h}$ at $4^{\circ} \mathrm{C}$. The extract was filtrated through a filter paper (Toyoroshi No. 2) to remove gross debris. It was centrifuged at $5,000 \mathrm{rpm}$ for $30 \mathrm{~min}$ and the supernatant was then passed through a millipore filter (pore size $0.45 \mu \mathrm{m}$ ). Concentration of the extract was performed by ultrafiltration with UM 05 Diaflo membrane (Amicon corporation USA). To a portion of the extract $(50 \mathrm{~m} l)$ was added ammonium sulfate to give a final concentration of $70 \%$ saturation. The precipitate was dissolved in distilled water, dialyzed, and made up to $5 \mathrm{~m} l$.

\section{Assay of Hemagglutinating Activity}

A serial two-fold dilution of the test sample was made in microtiter plate wells with $25 \mu \mathrm{l}$ of PBS. An equal volume of $2 \%$ erythrocyte suspension in PBS was added to each well. The plate was kept with gentle agitation at $37^{\circ} \mathrm{C}$ for $30 \mathrm{~min}$, and successively left to stand at room temperature for $2 \mathrm{~h}$. Hemagglutinating titers were expressed as the reciprocal of the highest sample dilution rate exhibiting positive hemagglutination.

Protein and carbohydrate concentrations were determined by means of the Coomassie brilliant blue method reported by Bradford ${ }^{102}$ and by the

* The Yamagata Prefectural Institute of Public Health. 6-6, Tohkamachi 1, Yamagata, Yamagata 990 , Japan (高橋裕一, 片桐 進: 山形罡衛生研究所). 
phenol-sulfuric acid method, ${ }^{11}$ respectively.

\section{Gel Chromatography}

$1.0 \mathrm{~m} l$ of the extract concentrated by ten times with ultrafiltration was applied onto a column $(2.5 \times 30 \mathrm{~cm})$ of Toyopearl HW-55S (Toyosoda, Tokyo), which had been equilibrated with PBS. The column was eluted with PBS at a flow rate of $20 \mathrm{ml} / \mathrm{h}$. Fractions of $2 \mathrm{ml}$ were collected and were analyzed for absorption at $280 \mathrm{~nm}$ and for hemagglutinating activity for goose and horse erythrocytes. Immunoglobulin G (MW $160 \mathrm{~K}$ ), human serum albumin (MW $67 \mathrm{~K}$ ) ovalbumin (MW $45 \mathrm{~K}$ ) used as markers were purchased from Serva Feinbiochemica (West Germany), Miles Laboratories (USA), and Seikagakukogyo (Japan), respectively. Low density lipoproteins (MW 2,000 $\mathrm{K})$ purified from human serum ${ }^{122}$ and $\beta_{2}$-microglobulin $\left(\mathrm{MW} 11 \mathrm{~K}\right.$ ) from human urine ${ }^{13)}$ were also used as markers.

\section{Isoelectrofocusing Analysis}

$4.5 \mathrm{~g}$ of Sephadex IEF (Pharmacia Fine Chemicals) were swollen in $50 \mathrm{~m} l$ of distilled water. To the deaerated Sephadex gel, $5.0 \mathrm{~m} l$ of the Ampholine ( $\mathrm{pH}$ range 3.5-6.0) was added, and the Ampholine gel was spread onto a horizontal plate $(25 \times 10 \times 0.2 \mathrm{~cm})$. The extract concentrated by ten times with ultrafiltration was applied in the central part of the gel plate. $0.1 \mathrm{M}$ phosphoric acid was used for the anode solution and $0.1 \mathrm{M}$ $\mathrm{NaOH}$ for the cathode solution. The electrophoresis was performed for $48 \mathrm{~h}$ at a constant voltage of $50 \mathrm{~V} / \mathrm{cm}$.

After electrophoresis, the gel was fractionated into 15 equal sections. To each fraction, $5 \mathrm{ml}$ of distilled water was added, and then each fraction was passed through a filter paper (Toyoroshi No. 2). Ampholine was removed by dialysis against distilled water. All fractions were concentrated to $2 \mathrm{~m} l$ by ultrafiltration and the hemagglutinating activity against horse and goose erythrocytes were measured.

\section{Results}

\section{Hemagglutinating Activities of the Extracts to Various Kinds of Erythrocytes.}

The activities of the extracts were measured using ten kinds of mammal erythrocytes (Table 1). Higher hemagglutinating activities were observed in horse and goose, and lower activities in the others. From these results, the activity was measured with horse and goose erythrocytes in the
Table 1. Hemagglutinating activities of the extracts to the erythrocytes of various animals

\begin{tabular}{|c|c|c|}
\hline Blood cells & Crude extract & $\begin{array}{l}\text { of } \\
\text { Ammonium } \\
\text { sulfate } \\
\text { precipitate*1 }\end{array}$ \\
\hline Horse & 64 & 512 \\
\hline Rabbit & 16 & 64 \\
\hline Mouse & 4 & 16 \\
\hline Human A & 8 & $\mathrm{ND}^{* 2}$ \\
\hline B & 16 & 32 \\
\hline $\mathrm{O}$ & 8 & ND \\
\hline $\mathrm{AB}$ & 8 & ND \\
\hline Pig & 16 & 64 \\
\hline Goose & 32 & 256 \\
\hline Chicken & 16 & 128 \\
\hline
\end{tabular}

"1 Precipitate obtained by addition of ammonium sulfate $(70 \%$ saturation) was made up to one-tenth volume of the original extract.

*2 not done.

following experiments.

\section{Seasonal Variation of Hemagglutinating Activities}

Changes in hemagglutinating activity of the extracts of $G$. verrucosa which were collected in Ehime and Nagasaki Prefectures at various months are shown in Fig. 1. In the Ehime specimens, the activities against both horse and goose erythrocytes were detected from November to next June. In particular, hemagglutinating activity was high during the period of November to next February, while undetectable in July and August. Similar results were also found in the Nagasaki specimens. Thus the seasonal variation of the activity to horse or goose erythrocytes was shown in both specimens collected at Ehime and Nagasaki Prefecture.

\section{Fractionations of Hemagglutinins from the Extract}

First, the extract of the alga collected at Ehime in February was fractionated by isoelectrofocusing on Sephadex IEF in the range of pH 3.5 and 6.0. The hemagglutinating activity of the extract was separated into two peaks of isoelectric points at pH 4.2 and 4.7 as shown in Fig. 2. The former agglutinated only horse erythrocytes but not goose ones, and the latter was agglutinable both horse and goose erythrocytes.

Next, we performed the fractionation of the extract of $G$. verrucosa collected at Ehime in May on a Toyopearl HW-55S column. As shown in Fig. 3, three active peaks against horse erythrocytes with a mean molecular weight of approximately $300-400 \mathrm{~K}$ (peak I), $100 \mathrm{~K}$ (peak II) and $45 \mathrm{~K}$ (peak III) were detected. Activity of the peak I and peak II were detected with horse erythrocytes 

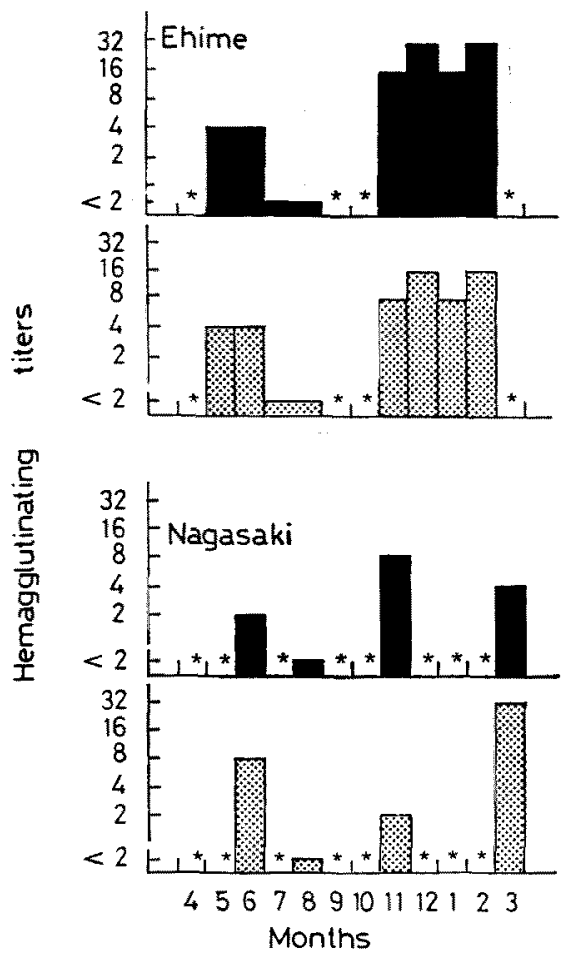

Fig. 1. Seasonal variation in hemagglutinating activity of Gracilaria verrucosa.

Hemagglutinating activity of the extracts of the alga collected at Ehime and Nagasaki Prefecture in different months was compared by using horse and goose erythrocytes.

hemagglutinating titer for horse erythrocytes, $\$$. hemagglutinating titer for goose erythrocytes. * not tested.

but not with goose ones. Peak III was found to agglutinate both kinds of animal blood cells. To know whether or not the seasonal variation is present in the hemagglutinin constituents of $G$. verrucosa, the elution patterns of the hemagglutinins from a Toyopearl HW-55S column were compared by using the algal extract with different collection date. As shown in Fig. 4 neither peak I nor peak II was detected in the Ehime specimens collected in November. These two peaks started to appear in December, and were also found in February. Peak III was detectable in every algal extract examined. On the other hand, in the case of Nagasaki specimens three peaks corresponding to the peak I, II and III were observed in both November and March, though the activity of peak I and II was much lower than that of peaks in March.

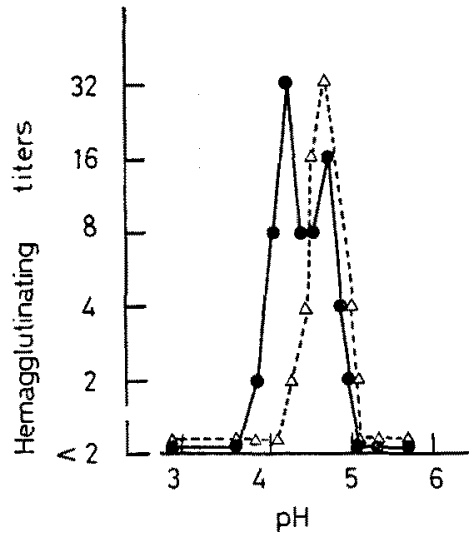

Fig. 2. Isoelectric focusing of Gracilaria verrucosa hemagglutinins.

Isoelectric focusing of $G$. verrucosa extract was conducted on Sephadex IEF plate $(25 \times 10 \times 0.5$ $\mathrm{cm}$ ) in the range of pH 3.5 and 6.0. The algal sample used was collected at Ehime Prefecture in February. After electrophoresis, the gel was fractionated, extracted with distilled water, and estimated for hemagglutinating activity against horse $(-)$ ) and goose $(\triangle \cdots \Delta)$ erythrocytes.

\section{Discussion}

In the present study, it was demonstrated that three different hemagglutinins existed in the red alga Gracilaria verrucosa. They were proteins in nature, and were different from one another in the molecular size, in isoelectric point and in hemagglutinating activity against horse and goose erythrocytes. One of them (MW $45 \mathrm{~K}$ and $\mathrm{pI}$ 4.7) could agglutinate both of horse and goose erythrocytes. This hemagglutinin may be identical to the hemagglutinin reported previously as GVA-1 by Shiomi et al. ${ }^{8}$ The other two, which were agglutinable horse erythrocytes but not goose erythrocytes, were $300-400 \mathrm{~K}$ and $100 \mathrm{~K}$ in molecular weight, and showed the same isoelectric point at $\mathrm{pH} 4.2$. The occurrence of $300-400 \mathrm{~K}$ and $100 \mathrm{~K}$ components in this red alga may be the first finding. However, the relationship between these components was unclear.

The $45 \mathrm{~K}$ hemagglutinin (pI 4.7) was detected during the period of November to next March, and the hemagglutinins with higher molecular weight and lower isoelectric point (pI 4.2) were detectable during the period of December to February or March but little or not in November (Fig. 4). These results suggest that the production period of pI 4.7 and 4.2 hemagglutinins was different from each other. 


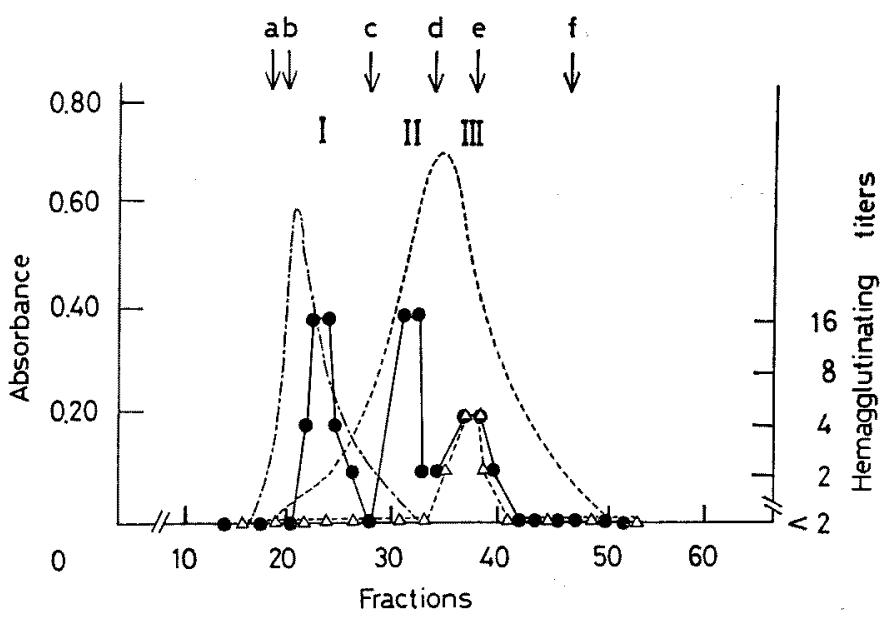

Fig. 3. Gel filtration of Gracilaria verrucosa extract on Toyopearl HW55-S.

The extract of $G$. verrucosa collected at Ehime in May was fractionated on a Toyopearl HW-55S column $(2.5 \times 30 \mathrm{~cm})$. Elution buffer was $0.05 \mathrm{M}$ phosphate buffered saline ( $\mathrm{pH}$ 7.0). Fractions of $2 \mathrm{~m} l$ were collected. The following markers were used: a; blue dextran, b; low density lipoproteins, $c$; immunoglobulin $G$, d; human serum albumin, e; ovalbumin, f; $\beta_{2}$-microglobulin. - hemagglutinating titer for horse erythrocytes, $\Delta---\Delta$ hemagglutinating titer for goose erythrocytes, - - absorbance at $595 \mathrm{~nm}$ in Bradford method for proteins, - _ absorbance at $490 \mathrm{~nm}$ in phenol- $\mathrm{H}_{2} \mathrm{SO}_{4}$ method for carbohydrates.

Life-history of Gracilaria verrucosa is consisted of three generations, i.e. a sporophyte, a gametophyte and a carposporophyte generation. ${ }^{14)}$ The carposporophyte generation is parasitic on the gametophyte generation. The sporophyte generation is from November to June and the other generations are from May to September in the central part of Main Land of Japan.* We confirmed that the algal specimens which were collected in July and August showed no hemagglutinating activity and that they had a large number of cystocarps. In addition, the specimens in November were smaller in size when compared with those collected in December, February and March. It is assumed that the greater part of the algae collected in November to March were sporophyte generation, although we could not histologically confirm that these algae were sporophyte generation. These findings suggest that $G$. verrucosa hemagglutinins are produced in its sporophyte generation and is unrelated to gamate recognition as reported in the macromolecular factors in some dioecious fucoid seaweeds. ${ }^{15-17}$ )

\section{Acknowledgments}

The authors thank the personnels in the Ehime
Prefectural Institute of Public Health and in the Department of Health and Environment of Nagasaki Prefecture for the supply of the algae. We are also grateful to Mrs. H. Takeda of The Yamagata Prefectural Inspection Center of Edible Meat, for supply of horse bloods. This work was supported by a Grant-in-Aid for Scientific Research from Department of Health and Environment of Yamagata Prefecture.

\section{References}

1) G. A. Ingram: Dev. Comp. Immunol., 9, 1-10 (1985).

2) H. Kamiya: Kagaku to Seibutsu, 23, 779-786 (1983).

3) D. J. Rogers and G. Blunden: Bot. Mar., 18, 459-462 (1980).

4) K. Shiomi, H. Kamiya, and Y. Shimizu: Biochim. Biophys. Acta, 576, 118-127 (1979).

5) K. Shiomi, H. Yamanaka, and T. Kikuchi: Nippon Suisan Gakkaishi, 46, 1369-1373 (1980).

6) H. Kamiya, K. Shiomi, and Y. Shimizu: Lloydia, 43, 136-139 (1980).

7) K. Hori, K. Miyazawa, and K. Itoh: Nippon Suisan Gakkaishi, 52, 323-331 (1986).

8) K. Hori, K. Miyazawa, and K. Itoh: Nippon Suisan Gakkaishi, 47, 793-798 (1981).

9) K. Shiomi, H. Yamanaka, and T. Kikuchi:

* K. Akiyama; The Tohoku Regional Fisheries Research Laboratory, personal communication. 

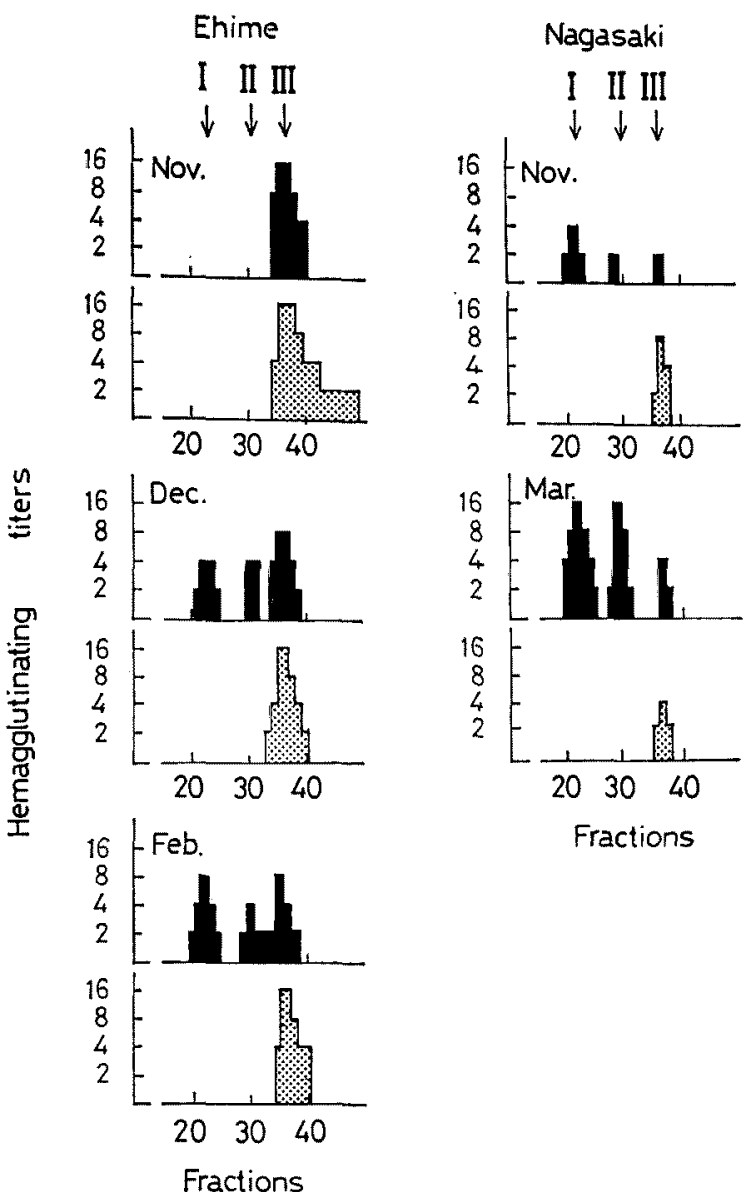

Fig. 4. Gel filtration of the extract of Gracilaria verrucosa collected in different months.

The extract of $G$. verrucosa collected at Ehime and Nagasaki Prefecture in different months was fractionated on a Toyopearl HW55-S column. Fractions were analyzed for hemagglutinating activity against horse $\left({ }_{-1}\right)$ and goose (B) erythrocytes.

Nippon Suisan Gakkaishi, 47, 1079-1084 (1981).

10) M. Bradford: Anal. Biochem., 72, 248-253 (1976).

11) M. Dubois, K. A. Gills, J. K. Hamilton, P. A. Rebers, and E. Smith: Anal. Chem., 28, 350-356 (1956).

12) Y. Takahashi, K. Uruno, and S. Kimura: $J$. Nutr. Sci. Vitaminol, 23, 201-209 (1977).

13) Y. Takahashi and K. Uruno: Yamagata J. Med., 15, 17-21 (1981).
14) J. Mclachlan and T. Edelstein: J. Mar. Bio. Ass. U.K., 57, 577-586 (1977).

15) G. P. Bolwell, J. A. Callow, and L. V. Evans: Nature, 268, 626-627 (1977).

16) G. P. Bolwell, J. A. Callow, and L. V. Evans: $J$. Cell Sci., 43, 209-215 (1980).

17) J. W. Catt, H. I. M. V. Vithanage, J. A. Callow, M. E. Callow, and L. V. Evans: Exp. Cell Res., 147, 127-133 (1983). 